\title{
Arteterapia \& artes visuais: aproximações contemporâneas
}

Robson Xavier da Costa

\section{Resumo}

Este ensaio objetiva discutir teoricamente a relação entre a arteterapia e as artes visuais, a partir da leitura comparativa dos procedimentos desenvolvidos pelo arteterapeuta, comparados analogicamente com práticas comuns do contexto das artes visuais. Utilizamos como base teórica, a abordagem analítica e simbólica de Jung (2005); os conceitos da arteterapia em Paín (2009) e Ciornai (2004); de arte contemporânea em Cauquelin (2005) e Chocchiarale (2006). Como método, trabalhamos com a argumentação teórica, comparando literatura e práticas profissionais do arteterapeuta. A partir da argumentação central do texto, consideramos que, é fundamental garantir a formação adequada na área de artes visuais para os profissionais oriundos dos cursos de formação/ especialização em arteterapia no Brasil, visando equilibrar a dicotomia entre os conteúdos e práticas em psicologia e em artes visuais ministrados nesses cursos no pais.

Palavras-chave: Arteterapia. Artes Visuais. Arte Contemporânea.

\section{Abstract}

This paper discusses theoretically the relationship between art therapy and the visual arts, from the comparative reading of the procedures developed by art therapist, analogically compared with common practices of the context of the visual arts. The base of the symbolic and theoretical and analytical approach it is Jung (2005); the concepts of art therapy in Paín (2009) and Ciornai (2004); and contemporary art in Cauquelin (2005) and Chocchiarale (2006). The method of work with the theoretical argument, comparing literature and practices of the art therapist. From the central argument of the text, we believe, is crucial to ensure adequate training in the field of visual arts for professionals from the training courses/specialization in art therapy in Brazil, aiming to balance the dichotomy between content and practice in psychology and visual arts taught in these courses in the country.

Key Words: Art Therapy. Visual Arts. Contemporary Art. 


\section{Artes visuais e arteterapia}

O mundo artístico atual legitima o uso metafórico da palavra "arte" em terapia. A arteterapia é em conseqüência a instituição que faz da arte uma metáfora, um lugar social onde o indivíduo age "como se" fosse artista (PAÍN, 2009, p. 17).

O conhecimento das artes visuais é central na formação do arteterapeuta, a compreensão da diversidade do conceito de arte em diferentes períodos históricos e as possibilidades da utilização da arte contemporânea como recurso para a práxis no setting arteterapêutico podem ser vistos como diferenciais na atuação do arteterapeut ${ }^{19}$. Considerando que inúmeros arteterapeutas no Brasil são profissionais emergentes dos cursos das áreas de Saúde e Psicologia, se faz necessário que os cursos de formação e especialização em arteterapia fomentem o conhecimento sobre o universo das artes visuais e de outras linguagens artísticas para a sua aplicação coerente no cotidiano do ateliê terapêutico. Discutir como o conhecimento das artes visuais pode contribuir para o aprimoramento da atuação do arteterapeuta pode auxiliar em novos direcionamentos da formação em arteterapia no país.

Para repensarmos o papel da arte na formação do arteterapeuta, se faz necessário indagarmos, inicialmente, qual o conceito de arte veiculado nos cursos de formação/ especialização de arteterapia no Brasil? Pergunta de difícil resposta, que tem relação com: a formação dos professores e dos alunos desses cursos e a maneira que concebem o conceito de arte, diante das inúmeras transformações na arte ocorridas ao longo dos séculos; a quase infinita ampliação das possibilidades para a produção artística com o advento da Arte Contemporânea, a partir de meados dos anos 1960 e a necessidade de artistas com formações de base multidisciplinares.

A arteterapia é possível hoje porque a arte libertou-se de toda norma canônica, de toda obrigação que não emane das regras de jogo que o artista inventa. Ela tem uma dívida com essa modalidade da atividade, própria da atividade artística, que lhe permite atuar em nome de uma estética supostamente espontânea na qual a obra se justifica por sua própria existência, conservando sempre as propriedades tradicionais do objeto [artístico]: gratuidade, ausência de utilidade, primado da forma sobre a função (PAÍN, 2009, p. 12).

Aparentemente já é difícil à compreensão da arte contemporânea para maioria

19 O termo arteterapeuta pode ser substituído pela abreviação ARTT, sigla recomendada no documento intitulado "Carta de Canela" (2008), aprovado pela diretoria da União Brasileira de Associações de Arteterapia - UBAAT, para designar a abreviação do termo Arteterapeuta no Brasil. 
dos alunos dos cursos de graduação em artes visuais, já que os conceitos se chocam com as crenças arraigadas entre o discurso da arte como beleza, harmonia, criatividade, expressão, que muitos alunos trazem como base ao ingressar nas universidades, no caso dos profissionais oriundos de outras áreas de conhecimento, que não estudam diretamente as manifestações artísticas no currículo nos seus cursos de graduação, esse problema é mais significativo. No Brasil, algumas pessoas chegam a passar toda a vida sem ter contato com um trabalho de arte ou mesmo a frequentar um museu, pensando nesse fato, faz-se necessário fomentar a frequentação às artes na formação/especialização do arteterapeuta brasileiro.

Tal qual o professor de artes visuais, o arteterapeuta trabalha diretamente com pessoas e com o conhecimentos humanos, enquanto o professor está preocupado com a formação e a construção do conhecimento, o arteterapeuta busca tornar-se um facilitador no processo de autoconhecimento do $\operatorname{artistant}^{20}$, seja em atendimentos individuais ou em grupo. Em parte, a ação do arteterapeuta no setting pode ser comparada ao processo do artista em seu ateliê, ambos lidam com universos de conhecimentos estranhos, que não estão previamente determinados, são formas de saber, processadas ao longo do desenvolvimento do trabalho, a descoberta é parte integrante do processo, tornando a sua atuação interessante e dinâmica. Tal qual a arte contemporânea, a arteterapia nega a existência de modelos pré-determinados para sua produção visual, permitindo aos participantes experimentação e descoberta. Segundo Cocchiarale (2006) "o artista contemporâneo nos convoca para um jogo onde as regras não são lineares, mas desdobradas em redes de relações possíveis ou não de serem desdobradas".

No ateliê, a falta de conhecimentos artísticos do artistant faz com que frequentemente suas representações sejam confusas, feias, violentas, desordenadas ou ingênuas. Todas essas modalidades são consequências da passagem da emoção à tela praticamente sem a mediação de um conhecimento técnico. De fato, a arte contemporânea aceita uma multiplicidade de valores contraditórios, com movimentos intempestivos, provocando espanto, riso, angústia ou náusea (...) (PAÍN, 2009, p. 15).

Se o processo arteterapêutico é de permanente experimentação, uma exigência para a prática do arteterapeuta é que ele não pode ser regido por nenhum tipo específico de modelo prévio, todos os estilos e concepções de produções visuais podem ser utilizados no ateliê, desde que sejam significados ao longo do caminho para o artistant. $\mathrm{Na}$ arteterapia, fruição e interação são centrais, para dar significado às imagens criadas e observadas, que devem interagir, dialogar e ser manipuladas, levando o artistant a

20 Termo citado por Sarah Paín no livro "os fundamentos da arteterapia”, traduzido e publicado em 2009 no Brasil, para designar o sujeito que se submete ao processo arteterapêutico. 
reconhecer-se no processo de produção visual, essas imagens podem ser mediadas pelas palavras, a explicação oral geralmente é posterior à criação e se insere na leitura da imagem.

Se a prática da arteterapia pretende ou se afirma como um processo terapêutico não verbal, porque a necessidade da palavra? Sabemos que muitas vezes a imagem pode chegar a ser inteligível, sua interpretação depende da decifração dos códigos e símbolos, consequentemente da mediação do especialista na leitura. No caso do setting arteterapêutico a mediação é realizada pelo arteterapeuta em diálogo com o artistant, onde a imagem passa a ser o objeto transferencial, como a leitura da imagem é ampla e múltipla, os personagens do processo podem tecer leituras diferenciadas, até mesmo opostas, sobre a mesma imagem. A palavra, como forma de interpretação do artistant sobre sua produção, pode auxiliar a resolução dos conteúdos emergentes nas imagens, compreendidos como elementos projetivos. Utilizando a produção e leitura de imagens, a arteterapia facilita o contato entre o arteterapeuta e o artistant, o processo pode ser avaliado pela qualidade da interação visual, a minimização de barreiras simbólicas, a abertura para o onírico, o inconsciente e a utilização do potencial lúdico da produção artística.

No ateliê terapêutico ocorre um processo, que por analogia aproxima-se de uma curadoria artística, enquanto no museu, o curador dispõe de um conjunto de obras que serão selecionadas partindo de uma tema gerador ou propõe a criação de obras específicas para determinados espaços, o arteterapeuta, tem imagens a disposição no ateliê, que são produzidas em um determinado contexto, partindo de consignas definidas ao longo do processo de interação entre o artistant e o arteterapeuta. O roteiro crítico ou textos de uma exposição podem ser comparados ao diálogo ou mesmo à escrita espontânea surgida ao longo do trabalho do arteterapeuta. Tanto as exposições e/ou as imagens são objeto de leituras pelo público, como na arteterapia as imagens são lidas pelos envolvidos no processo, o que ocorre na prática é uma pesquisa plástica formal (produção e leitura de imagens), perceptiva e expressiva diante das imagens produzidas e/ou observadas pelo grupo ou artistant. Segundo Paín:

Reciprocamente, podemos falar que a arteterapia ajuda a compreender a arte contemporânea. O louco pinta sua loucura, o débil mental pinta com a escassez dos seus recursos, e, assim, cada um encontra na atividade artística seu lugar, pois o ateliê apresenta-se como um espaço de tolerância, recebe a todos sem reservas (PAÍN, 2009, p. 19).

A relação entre a ateterapia e as artes visuais, principalmente a arte contemporânea, está inserida nos processos híbridos, multiculturais e experimentais da arte atual, têm relação intrínseca com a forma de trabalho do arteterapeuta no seu contexto específico, no ateliê ou setting arteterapêutico. Cabe aos cursos de formação e especialização 
em arteterapia no Brasil investirem de forma equilibrada na inserção de conteúdos e vivências na área de artes visuais em seus currículos, favorecendo a leitura e interpretação das imagens a partir do domínio dos códigos necessários para que a mesma se efetive com qualidade. $\mathrm{O}$ arteterapeuta não é um profissional exclusivo da área de saúde, mas um profissional que deve dominar também conhecimentos da área de Arte para aplicar na manutenção do bem estar e da saúde coletiva humana.

Nesse contexto, a arte pode ser um facilitador do contato entre o indivíduo consigo mesmo e com o seu entorno, a partir de conexões com conteúdos latentes do inconsciente coletivo e do domínio de técnicas, materiais expressivos e conhecimentos sobre arte.

\section{Relação entre arte \& vida}

[...] um dos grandes obstáculos para entender a arte contemporânea é o fato de ela ter-se tornado parecida demais com a vida. É como se, num processo de integração entre arte e vida, a arte tivesse doado tanto sangue para a estetização da vida que ela se desestetizou (COCCHIARALE, 2006).

A arte moderna e contemporânea aproximou os objetos do cotidiano do universo artístico, ao ampliar os materiais, as tecnologias utilizáveis e o acesso as interfaces digitais. Instaurou-se a experimentação como máxima. Na arteterapia objetos podem ser significados e resignificados ao longo do processo da produção de imagens, o contato com esses objetos depende da consigna e da demanda do artistant. Colagens, assemblages, objetos e instalações em composições diversas, no contexto do ateliê arteterapêutico, podem ser fortes aliados do procedimento terapêutico, induzindo as memórias latentes e fazendo conexões entre conteúdos conscientes e inconscientes. Cabe ao arteterapeuta utilizar esses recursos na prática cotidiana.

Diversas abordagens artísticas contemporâneas podem ser interessantes como ponto de partida para a prática arteterapêutica. A Street Art e a Arte da Periferia, são caminhos possíveis, emergindo das ruas para os espaços comerciais de arte nas últimas décadas, a partir dos circuitos alternativos urbanos, expressões como o grafitti, o hip hop, a capoeira, a dança de rua, as pinturas comerciais populares, conjunto extenso de imagens, partes integrantes da cultura visual contemporânea, foram valorizadas no Brasil, com a criação de galerias de arte especializadas como "A Choque Cultural" em São Paulo em 2003 e por exposições como a mostra "Estética da Periferia" realizada no Centro Cultural Correios do Rio de Janeiro em 2005 e no Museu de Arte Moderna Aloísio Magalhães (Mamam) no Recife em 2007, essa mostra foi um panorama da arquitetura, das artes vi- 
suais, da moda/comportamento e do design da periferia dessas cidades brasileiras. Essa forma de representação artística tem sido divulgada em todo o mundo por artistas grafiteiros como "os gêmeos" (São Paulo - 1974), que em 22 de maio de 2008, executaram a pintura da fachada da Tate Modern, de Londres, para a exposição Street Art.

A inserção nos circuitos comerciais da arte da periferia pode beneficiar o trabalho do arteterapeuta por permitir a ampliação de meios e técnicas expressivas que podem ser aplicadas no setting. Ao valorizar o potencial cultural do artistant e dos grupos atendidos, o arteterapeuta leva em conta a diversidade cultural de um país continental como o Brasil, devendo estar atento às informações visuais fornecidas pela malha urbana e pelos indícios do layout produzidos pelos próprios artistants, presentes no look das pessoas e no visual comercial do entorno da instituição, é o olhar especializado sobre as informações visuais disponíveis no contexto do trabalho arteterapêutico.

No processo arteterapêutico a imagem é lida como conteúdo, como parte de um conjunto de variáveis que podem levar a compreensão do sujeito diante dos seus próprios conflitos psíquicos. No mundo contemporâneo a crise do sujeito é um reflexo das inúmeras transformações sociais, econômicas e culturais, oriundas do processo de globalização do capitalismo, as imagens contemporâneas são potencializadas por uma cultura de massa totalizadora, mediada pelas tecnologias da informação e comunicação e banalizadas pelo excesso de informações visuais que nos envolvem no cotidiano. A crise da identidade do sujeito pode ser representada pelo mundo das imagens.

Certamente que ao não ser o artistant um artista, a atividade que realiza em nome da arte não é, em absoluto, arte. Na arteterapia, a arte é concebida como uma metáfora, ou melhor, algo que se assemelha à arte, indicada por sua dupla condição: por um lado, aquele que freqüenta $o$ ateliê não se compromete com o aprendizado sistemático das regras do ofício, nem com a criação de ideias plásticas cuja coerência estética seja completa e socialmente reconhecida; por outro lado, a arteterapia demanda da arte um serviço útil. Este serviço terapêutico constitui a própria definição de arte, projetando simultaneamente sobre o paciente a tensão contraditória inerente à possibilidade de cura (PAÍN, 2009, p. 12).

A ação do arteterapeuta deve se pautar em uma conduta transdisciplinar e multicultural, sua prática aberta e acolhedora, deve estar acima das diferenças e mapear a possibilidade das habilidades individuais e coletivas para aprimorar o ser humano na busca da harmonia pessoal e coletiva. $\mathrm{O}$ arteterapeuta deve ser um profissional atualizado com as possibilidades da tecnologia de seu momento histórico, para que as mesmas sejam úteis no cotidiano do ateliê, como forma de mediar as relações entre as pessoas, mesmo utilizando a pintura, o desenho ou a gravura, tecnologias que em determinado 
momento da história humana foram revolucionárias, mas que hoje são hoje consideradas tradicionais nas artes visuais. No ateliê arteterapêutico técnicas tradicionais e atuais podem e devem dialogar favorecendo o desenvolvimento do cuidado com o processo pessoal do artistant.

Tal como a natureza humana está em permanente processo de transformação, a mudança contínua permite que os indivíduos se reconstruam emocional e psiquicamente mesmo diante de grandes perdas ou conflitos emocionais, a arte pode ser um meio mediador para esse processo, favorecendo o contato com o que há de mais íntimo do ser humano, o potencial simbólico. Por meio da arteterapia o sujeito pode reconstruir sua própria história, após tomar contato com suas imagens interiores, pode ser capaz de dialogar com sua sombra e seus complexos, apreender e conviver com suas potencialidades e fraquezas.

A arteterapia possibilita que o indivíduo seja um produtor expressivo e seu próprio crítico, aquele que faz e que analisa a produção. Se a palavra Krisís do grego separar, distinguir, escolher, julgar, pode ser aplicada ao julgamento crítico em arte, também pode ser aplicada à leitura das imagens realizadas pelo próprio artistant em seu processo arteterapêutico. De certa forma, ele julga sua própria produção visual, separando, distinguindo e escolhendo o que nas imagens são símbolos importantes para sua própria trajetória. Como em toda crítica a imparcialidade é desejada, mas não concretizada, seu olhar está contaminado pelos seus próprios desejos egóicos, nesse momento entra a figura do arteterapeuta para intermediar a situação e apresentar um olhar externo ao processo. $\mathrm{O}$ arteterapeuta tem que desempenhar com alteridade e isenção sua atuação nesse momento, sem necessidade de especificar avaliações sobre as imagens e o processo terapêutico, apenas mediando à relação contra transferencial entre a imagem e o artistant.

O que podemos inferir dessas relações citadas é que a produção no ateliê arteterapêutico não objetiva ser arte, mas potencialmente pode vir a ser, como é o caso do trabalho dos internos do Hospital Psiquiátrico do Engenho de Dentro, do ateliê de terapia ocupacional, hoje parte integrante do Museu de Imagens do Inconsciente, onde internos esquizofrênicos, pacientes da Dra ${ }^{\mathrm{a}}$. Nise da Silveira, tornaram-se artistas conhecidos em todo o mundo devido à qualidade visual das suas obras e também da Colônia Juliano Moreira no Rio de Janeiro, onde surgiu a figura emblemática de Arthur Bispo do Rosário, considerado um importante representante da arte contemporânea brasileira.

Embora o objetivo da arteterapia não seja a formação de artistas, é possível, que o processo de desbloqueio criativo possibilitado pela prática da arteterapia, desencadeie o potencial de alguns indivíduos e estes possam revelar suas habilidades artísticas. $\mathrm{O}$ processo arteterapêutico pode ser aplicado a qualquer ser humano, em qualquer idade, desde que se respeitem os limites e potencialidades dos envolvidos. Cabe também res- 
saltar que é fundamental para o arteterapeuta trabalhar em uma equipe multidisciplinar, com profissionais de áreas afins, acompanhando o mesmo artistant, para que a visão da totalidade sobre o estado de saúde mental da pessoa atendida seja resguardada.

\section{Arte: invenção ou conceito}

A arte contemporânea instituiu o conceito como elemento central na prática artística, $\mathrm{o}$ artista tornou-se novamente um profissional da elaboração do projeto (tal qual o artista renascentista), pensar sobre o processo e elabora-lo como uma ideia coerente e de significado complexo passou a ser uma necessidade do artista contemporâneo.

É a partir da arte contemporânea que se pode falar da encarnação de ideias, embora no sentido "subjetivo" e singular do termo: cada obra apresenta-se como uma ideia que se representa por si mesma, de maneira tal que, nela, ser e representação coincidem. A tarefa terapêutica muda de foco quando abandona a hipótese de uma prioridade temporal da ideia sobre sua representação circunstancial. $\mathrm{O}$ importante é a emergência de uma ideia plástica no sujeito que não seja nem anterior ao gesto de realizá-la nem pré-fabricada, mas elaborada à medida que a obra é realizada (PAÍN, 2009, p.13).

A incorporação da apropriação de elementos de outras imagens na criação artística contemporânea aproximou as artes visuais da citação literária, as referências passaram a ser utilizadas como fontes possíveis para a criação, como atestam trabalhos de artistas como na obra Las Meninas (1957) de Pablo Picasso ao reler a obra-prima Las Meninas (1656) de Diego de Velásquez, ou como o conjunto da obra de Vick Muniz, que costuma buscar referências visuais em obras de arte para compor a base de suas releituras fotográficas. A possibilidade de fazer referências visuais, pastiche e paródia à obras existentes, pode ser um processo útil no setting terapêutico, possibilitando ao artistant buscar referências simbólicas em imagens já conhecidas e significá-las em outro contexto, a criação pode ser mediada pela apropriação dessas imagens.

O artista contemporâneo também recorre ao uso de serviços de terceiros para a execução de suas obras, contratando técnicos para o desenvolvimento de etapas específicas do projeto artístico. A delegação do fazer artístico passou a ser parte integrante do processo, o artista não é necessariamente aquele que coloca a mão na massa, é o mentor de um projeto elaborado do qual o executor é um habilidoso artesão. Arte e projeto artístico se confundem, podendo serem incluídos num processo de linha de montagem, como desejava Andy Warhol em sua famosa Factory, sua residência ateliê na East 47th Street, Manhattan, Nova Yorque, onde residiu a partir de 1963, nesse ateliê coletivo, vários trabalhos projetados pelo artista eram executados pelos aprendizes, que residiam e 
trabalhavam nesse espaço, a partir de fotografias em Polaroid realizadas pelo artista. A Factory foi um bem sucedido espaço experimental de arte, por onde transitaram os mais importantes artistas e intelectuais americanos nos anos 1960.

A partir da Factory a arte contemporânea passou a incorporar os elementos das novas tecnologias na execução e na elaboração dos projetos artísticos, cada vez mais o artista aproxima-se de um cientista experimental, como demonstra as experimentações da Bioart ${ }^{21}$ é o caso da obra do artista brasileiro Eduardo Kac, que utiliza em seus trabalhos manipulação genética de ponta. Podemos pressentir uma forte tendência da experimentação biônica que almeja aproximar a tecnologia dura (mecânica) da tecnologia mole (biológica) para criação de híbridos.

A arteterapia enquanto processo criativo ainda está distante de incorporações desse porte, já que na maioria das vezes o arteterapeuta lida com materiais e técnicas ainda convencionais, como a pintura, a colagem, a gravura, a escultura, a modelagem, etc. Entre as novas tecnologias incorporadas ao processo arteterapêutico a fotografia e o vídeo são possibilidades bem plausíveis. Incluídas no setting terapêutico inicialmente como registro do processo, passaram depois, a serem incorporadas como meios técnicos expressivos, onde o artistant pode manipular máquinas e equipamentos e editar as imagens produzidas, o efeito dessas produções no processo arteterapêutico pode ser comparado ao uso de técnicas convencionais, com a vantagem de não exigir domínio artístico para a elaboração das imagens, apenas a possibilidade de conhecimento técnico do equipamento, deve ser mediado pelo terapeuta. Com a popularização do celular, do Ipod e do notebook o contato com a produção das imagens digitais passou a ser incorporado ao cotidiano de grande parte da população letrada, o que facilita o uso e a incorporação desses equipamentos no ateliê arteterapêutico.

Nos ateliês de arte, temos o privilégio de assistir pessoalmente a elaboração de uma obra, acompanhando de perto o exercício dos hábitos motrizes, as buscas, os arrependimentos, as provisões do artistant. Por vezes, temos a oportunidade de ver a obra surgir e desaparecer, completar-se e esvaziar-se, obra que é o campo de batalha que se ganha ou se perde (PAÍN, 2009, p. 14).

Se para o arteterapeuta o que importa não é a quantidade, nem a qualidade das imagens produzidas, mas o grau de significação pessoal e coletiva das mesmas durante o processo, devemos pensar que nem tudo aquilo o que vemos pode ser considerado imagem, a imagem requer um grau de relação mais intensa entre quem observa e aquilo que se vê, para ser imagem um motivo tem que ser somado a um conceito.

21 Prática artística contemporânea que utiliza como feramenta a biotecnologia, manipulação genética e clonagem. 
O conceito tem relação com a forma, com a linguagem e com o legado pessoal e coletivo de determinadas produções visuais. Cada imagem está eivada de conceitos e traços culturais específicos, que podem ser mediados ou acessados de acordo com a relação teoria/prática aplicada sobre ela. O processo está intimamente ligado à forma de condução do arteterapeuta para a relação transferencial entre o artistant e o objeto visual criado e analisado. Mediação seria a palavra ideal para definir o papel do arteterapeuta no auxilio na significação das imagens para o desenvolvimento do processo de individuação do artistant. Segundo Jaffé:

O que na verdade interessa aos artistas de hoje é a união consciente de sua realidade interior com a realidade do mundo ou da natureza; ou, em última instância, uma nova união de matéria e espírito (s/d, p. 268).

Se considerarmos que vivemos em um mundo fragmentado, complexo e híbrido e que os seres humanos buscam encontrar seus próprios processos de interpretação sobre os fatos psíquicos e naturais, podemos ter ideia da importância do papel do arteterapeuta na construção de uma nova forma de relação com a vida. Ao proporcionar espaços de interação coletiva, estimular a contemplação de imagens (algo menosprezado pela sociedade atual, que valoriza o consumo rápido, inclusive da informação visual), criar locais de reflexão para os indivíduos, acompanhar esse processo com um olhar crítico e atendo, o arteterapeuta torna-se um profissional que estimula o bem estar coletivo, a reflexão sobre a inserção do ser humano no espaço e sua responsabilidade consigo mesmo, com o outro e com o planeta em que vive, mediada pela arte.

\section{Considerações finais}

Esperamos que a questão central desse capítulo, mapear a relação das artes visuais com a arteterapia, possa ser considerado um tema recorrente para a elaboração dos currículos de formação de arteterapeutas no Brasil e no mundo. Não é possível imaginar o arteterapeuta sem conhecimento sólido sobre Artes Visuais, bem como sobre Psicologia; ambas as áreas devem estar contidas nos currículos de arteterapia como componentes centrais da formação.

Uma boa formação em arteterapia deve equilibrar o conhecimento teórico com o prático, possibilitando ao arteterapeuta vivenciar o fazer artístico e submeter-se a aplicação da teoria em procedimentos concretos, a fim de fazê-lo tomar contato com as possibilidades de acontecimentos que porventura venham a ocorrer no setting. Para tanto, o domínio de técnicas artísticas é um primeiro passo para a compreensão das dificuldades do artistant ao executar qualquer trabalho expressivo, sem esse conhecimento o arteterapeuta não poderá exercer seu papel de facilitador do processo com a desenvoltura necessária. 
$\mathrm{O}$ arteterapeuta deve também estar atento às teorias atuais do domínio da leitura de imagens, para que possa estimular adequadamente o olhar do artistant sobre sua produção visual, acompanhando e estabelecendo links entre o processo pessoal do artistant e o amplo universo da Arte. Isso corresponde a necessidade do desenvolvimento da compreensão simbólica do arteterapeuta, processo que ocorre baseado em intensa leitura, prática contínua e cotidiana sobre a decodificação da simbologia visual. $\mathrm{O}$ arteterapeuta deve ser um conhecedor e fruidor das artes visuais, frequentação a exposições, museus, galerias e ateliês é uma forma de aprendizagem em processo, que deve fazer parte do métier do arteterapeuta, sem a qual, ele deixa de lado, um leque de conhecimentos indispensáveis para a sua atuação profissional.

O que apontamos é que o equilíbrio da ação clínica deve ter relação direta com a prática constante do desenvolvimento do potencial criativo do arteterapeuta. Conhecer artes visuais, os artistas, o processo criativo e o meio cultural, permite ao arteterapeuta utilizar essas informações para aprimorar sua práxis.

\section{Referências bibliográficas}

CAUQUELIN, Anne. Arte contemporânea: uma introdução. São Paulo: Martins Fontes, 2005.

CHOCCHIARALE, Fernando. Quem tem medo da arte contemporânea? Recife: Fundação Joaquim Nabuco, Ed. Massangana, 2006.

JAFFÉ, Aniela. O simbolismo nas artes plásticas. In: JUNG, Carl Gustav (Org.). O homem e seus símbolos. Trad. Maria Lúcia Pinto. $3^{\text {a }}$ Ed. Rio de Janeiro: Nova Fronteira, s/d, p. 230 a 270.

PAÍN, Sarah. Os fundamentos da arteterapia. Trad. Giselle Unti. Petrópolis - RJ: Vozes, 2009.

PERCURSO EDUCATIVO - isto é arte? E outras 10 perguntas freqüentes. Disponível em: www.itaúcultural.org.br. Acesso em: 13 de agosto de 2008.

RAVENA, Silvana Lacreta; SAVIANE, Iraci. História da arte vivenciada e arteterapia: um olhar poético para a história pessoal. In: CIORNAI, Selma (Org.). Percursos em arteterapia. São Paulo: Summus, 2004, p. 297-311. 